\title{
A educação diante da complexidade da sociedade contemporânea
}

\author{
Hans-Georg Flickinger
}

\section{Resumo}

Para acessar a complexidade da sociedade moderna, recorre-se à teoria geral de sistemas, em especial à concepção da "redução de complexidade", defendida por Niklas Luhmann. À base dessa teoria, o debate entre as principais visões pedagógicas é interpretado como discussão sobre o modo mais adequado de reduzir a complexidade que caracteriza, hoje, o campo da educação. Diante desse cenário, cabe às políticas educativas buscar soluções. Porém, nem a centralização europeia do sistema educativo, nem a estratégia brasileira de fortalecer a concorrência entre as instituições aí envolvidas escapam da armadilha intrínseca a qualquer modo de reduzir a complexidade.

Palavras-chave: Complexidade. Educação. Políticas educativas.

\section{Introdução}

O diagnóstico da sociedade contemporânea como sociedade de risco (BECK, 2010) virou lugar-comum, legitimando-se em razão da complexidade espantosa da vida moderna. Nela inseridos, os indivíduos não têm mais chance alguma de compreender e menos ainda de dominar o conjunto social como um todo. O sociólogo e jurista Niklas Luhmann falou da "complexidade incontrolável" do mundo moderno, que, apesar de sua lógica racional, conta com incertezas e riscos e, em consequência disso, com a ameaça permanente de uma das conquistas principais do iluminismo, isto é, da liberdade humana. Segundo o autor, o alto grau de complexidade da rede social gera "um risco intransponível" (1968, p. 38), que obriga os indivíduos a escolher modos específicos de lidar com a situação. A estratégia, descrita por Luhmann

Recebido: 15/08/2013 - Aprovado: 29/10/2013

http://dx.doi.org/10.5335/rep.v21i1.3869

Doutor em Filosofia pela Universidade de Heidelberg, Alemanha. Professor aposentado da Universidade de Kassel, Alemanha. 
como caminho escolhido pela sociedade moderna para enfrentar o problema, é a que ele denomina "redução da complexidade". Então, a primeira parte deste ensaio quer explicitar, de modo mais geral, o fundo teórico dessa opção.

É óbvio que a educação deve ser vista como fator importante na construção da ordem social. Ela tem de reagir, portanto, também à complexidade social e buscar maneiras de lidar com ela. Tratarei, na segunda parte, das políticas educativas sob esse viés, ou seja, como reações pragmáticas a esse desafio. Logo, as políticas serão interpretadas como estratégias de reduzir o cenário complexo.

$\mathrm{Na}$ terceira parte, remeterei ao debate político recente, o qual gira em torno da questão de conceder ou não um grau maior de autonomia às instituições educativas. O debate servir-me-á de exemplo para mostrar a dupla face das políticas educativas: para elas, a busca por modernas concepções pedagógicas significa, ao mesmo tempo, lutar pela redução da complexidade do campo pedagógico. O exemplo é atual, pois a questão da autonomia institucional, inicialmente discutida em relação às instituições da educação superior, tornou-se, ultimamente, também tema no que se refere à organização da rede escolar.

\section{0 acesso geral a sistemas sociais complexos}

Descrição e análise sociológicas da sociedade moderna baseiam-se, em geral, em dois tipos teóricos opostos. Por um lado, fala-se da teoria de ação, que toma a ordem social como resultado da negociação daqueles princípios, à base dos quais os interesses dos indivíduos deveriam ser avaliados e submetidos à decisão. Para sustentar essa visão, supõe-se indivíduos que, enquanto sujeitos livres, sejam capazes de escolher a organização adequada para alcançar esse objetivo. Por outro lado, defende-se a convicção de o grau de complexidade da sociedade hodierna impedir esse caminho, exigindo, antes de tudo, uma sua organização racional e flexível em vista da dinâmica da modernização social. Esse é o foco da teoria de sistemas, onde as pessoas figuram apenas como portadores de funções em prol da estabilidade da ordem social. É a organização social como sistema, cujo destino torna-se o referencial exclusivo dessa teoria, pois, enquanto a teoria de ação pressupõe indivíduos capazes de ler a construção da ordem social no seu todo, vendo nela a base da legitimação de seu comportamento, os defensores da teoria de sistemas argumentam com o alto grau da complexidade social que impossibilitaria seu acesso por parte dos indivíduos. Não seriam mais eles os sujeitos da construção social; ao contrário, o sistema social é que distribuiria os papéis e as responsabilidades sociais. Na verdade, a teoria de sistemas não pergunta pelo porquê do status quo da organização social e pelas razões que orientam a atuação de seus membros; ela se contenta 
com a descrição mais perfeita possível da estrutura real e da dinâmica de seu desenvolvimento. É exatamente essa capacidade que faz da teoria de sistemas uma ferramenta para tornar estruturas complexas transparentes e palpáveis.

Se consentimos na tese da crescente complexidade social, a opção pela teoria de sistemas para descrever e analisar a ordem social moderna impõe-se com certa naturalidade. Acho oportuno, por isso, caracterizar em poucas pinceladas os motivos que levaram à sua elaboração.

Historicamente falando, as raízes dessa teoria encontram-se na Biologia. A dificuldade dessa disciplina em entender um organismo amorfo levou-a a certificar-se, antes de tudo, de seu possível objeto de investigação. Para fazer do organismo vivo um objeto palpável, a Biologia viu-se obrigada a isolar e delimitar um conjunto vivo - por exemplo, da fauna ou flora - de seu ambiente. Assim transformado em sistema com marco delimitado, o organismo virou um possível objeto de experimentos científicos. Esse ato de "objetificação" permitiu tratar o organismo originalmente amorfo como um objeto qualquer, tornando possível descrever e analisar sua estrutura interna, observar a reação diante de manipulações externas, condicionar seu comportamento futuro, etc. A finalidade crucial dessa cirurgia científica foi a inserção do olhar objetivista na Biologia; assim, a Biologia passou a contar com o organismo como objeto da investigação científica (BERTALANFFY, 1977).

Como se sabe, a sociedade representa, também, um conjunto amorfo, sem contornos de antemão definidos. Em busca de driblar esse empecilho, a Sociologia viu nas experiências da Biologia o caminho certo de, assim como ela, conquistar sua cientificidade objetiva: submeter o todo social amorfo a um ato de objetificação virou o caminho para expor a realidade social à investigação científico-experimental. A teoria de sistemas trouxe o alívio, e não pode surpreender que sua atração cresceu à medida que a complexidade social real aumentou.

A transformação da realidade social em objeto científico mediante a teoria de sistemas significa, sem dúvida, uma vantagem valiosa, pois ela legitima aquela pretensão de objetividade, desde sempre visada pelas Ciências Sociais. Não demorou muito, por isso, até essa teoria descritiva ter conquistado seu reconhecimento também nesse campo. Ao avesso da euforia científica, porém, seus defensores pagavam um preço alto: foi necessário aceitar a primazia incondicional da racionalidade sistêmica em detrimento da autonomia do homem. Consta como perda o que se pode chamar a despotencialização do homem como sujeito de seu destino social. Aos indivíduos resta apenas cumprir funções que lhes são atribuídas pela racionalidade intrínseca ao sistema social. Desse modo, a abordagem sistêmica da sociedade complexa não aposta mais no homem como ser autônomo; muito pelo contrário, ela faz dele um mero "funcionário" servil de uma racionalidade obscura, 
a ele inalcançável, uma situação que o obriga a encontrar uma estratégia de lidar com a perda de sua soberania social.

O sistema substitui o homem como referencial decisivo da ordem social - eis, em resumo, o fio condutor da teoria de sistemas, que se opõe, assim, à teoria de ação e sua confiança na competência social dos atores individuais. Para encontrar seu lugar e poder agir dentro do sistema, os integrantes precisam de diretrizes orientadoras. A sociedade moderna tenta resolver essa situação difícil por meio da escolha de linhas de sentido e de sua inserção no todo social complexo, linhas de sentido que podem ser de cunho ético-moral, pragmático, profissional, ideológico, entre outros. Quanto maior a complexidade do sistema social, tanto maior a demanda por tais guias diferenciadoras, a fim de tornar o sistema manejável.

Pensemos, por exemplo, na esfera econômica. Ela representa um subsistema da sociedade que obedece à racionalidade utilitarista. Cada pessoa precisa submeter-se a esse critério sob pena de ficar fora do mercado de trabalho. No entanto, o comportamento da pessoa que se vê definido pela lógica econômica nem sempre é compatível, por exemplo, com princípios da justiça social, que, em hipótese, regem na esfera do Direito. Uma incompatibilidade que vale também em relação a outros subsistemas, entre os quais, o campo da educação. Cada subsistema orienta-se por critérios próprios, que, enquanto linhas seletivas de sentido, facilitam o manejo do todo. Com o olhar discriminador de tais linhas de sentido, o indivíduo busca driblar a complexidade social, a qual, como um todo, é inacessível. É essa a estratégia que Luhmann denominava de "redução da complexidade".

Por enquanto, a injeção de critérios de sentido no todo social, no intuito de facilitar a orientação em seu domínio, contemplou subsistemas sociais tais como economia, direito, trânsito, saúde, etc. Ela é observada, de fato, também no dia a dia dos indivíduos, ou seja, nos microcosmos sociais. Recorrerei a três exemplos para confirmar essa tese.

O primeiro exemplo refere-se à elaboração de um currículo pessoal. A biografia de uma pessoa é composta pelo conjunto amorfo de experiências e influências que nunca podem ser lembradas na sua íntegra. Quem se vê solicitado a escrever seu currículo pessoal não faz outra coisa senão inscrever ao seu passado uma linha de desenvolvimento em si mais ou menos consistente. Dependendo da expectativa do destinatário, cada currículo é produto do fio racional inscrito, ex post, na biografia. Cada currículo é, para assim dizer, resultado da orientação subjetiva dentro de uma vida passada complexa. No segundo exemplo, confirma-se essa observação. Falo da situação de profissionais de diferentes disciplinas que, trabalhando em equipe, devem pronunciar-se sobre um determinado assunto que lhes foi apresentado via relatório. É praticamente natural o que aí acontece: cada profissional vai interpre- 
tar o material a partir de seu olhar disciplinar, um olhar que atribui relevância a alguns fatores e negligencia outros, talvez de grande relevância para o colega da outra disciplina. Em outras palavras, cada um seleciona o material segundo o que lhe faz sentido como profissional. O olhar é um olhar seletivo em dependência do questionamento disciplinar.

O mesmo olhar seletivo opera no terceiro exemplo, isto é, em conflitos entre profissionais e burocratas numa instituição. Lembro apenas a luta do professor escolar que, para ajudar um aluno em situação de vulnerabilidade, defende a inclusão de familiares na solução do caso, mas se vê bloqueado pela administração da escola devido a questões não solúveis do seguro social. Aí, o projeto pedagogicamente aconselhado perde da racionalidade burocrática, que alega argumentos em si também coerentes e legítimos. Os dois lados recorrem a razões aceitáveis dentro da lógica de seu campo de agir, delimitando as respectivas responsabilidades profissionais.

Em todos os exemplos referidos, vale o mesmo raciocínio: lidar com a complexidade real exige sua "redução", no intuito de torná-la palpável, uma estratégia aparentemente atraente, porque permite a implementação de um fio condutor que, incluindo os fatores que lhe são compatíveis, negligencia, ao mesmo tempo, aqueles que não se integram na perspectiva escolhida.

Uma vez que o campo da educação vem sofrendo, também, o aumento dramático de sua complexidade, quero aproveitar a teoria de sistemas para a descrição e diagnose de seu manejo por parte da Política e dos pedagogos.

\section{Políticas educativas em busca da "redução da complexidade"}

A modernização sociopolítica e tecnológica, um processo dinâmico pelo qual o mundo hodierno vem passando, coloca desafios inéditos, desafios que exigem, além de inovações tecnológico-científicas, a revisão das formas de sociabilidade e a reorganização de suas instituições. Nesse contexto, o sistema educativo é visto como área importante da reação a esses desafios. O espaço pedagógico não escapa da acelerada complexificação de suas tarefas e se vê obrigado a buscar maneiras efetivas de seu manejo.

As decisões sobre o rumo das políticas educativas enfrentam um leque amplo de fatores novos. Trata-se não apenas de novas demandas externas e fora do alcance dos profissionais da área, como também da necessidade de dar conta delas através da reestruturação interna do campo profissional e institucional. Descrito em termos da teoria de sistemas, o sistema de educação vive a diferenciação estrutural causada por demandas provindas de subsistemas sociais externos - tais como 
da economia, da política, do direito, etc. - e pela necessidade de tornar sua própria estrutura interna capaz de reagir a essas expectativas, evitando, assim, o risco de sua própria derrocada. A complexidade crescente do espaço pedagógico resulta, portanto, de sua reestruturação interna para assimilar novos fatores externos. Somente assim esse sistema consegue salvar a autonomia diante das tentativas de sua instrumentalização por parte de interesses aleatórios. Visto sob esse ângulo, dá para interpretar o conflito acerca das diretrizes pedagógicas - conflito que desde sempre foi o fermento nos debates na Pedagogia - também como expressão do anseio de definir critérios de orientação para o trabalho profissional no campo cada vez mais complexo da educação. Por isso, vale a pena lançar um rápido olhar para esse debate.

É difícil dar uma ideia completa das diretrizes pedagógicas hoje discutidas. Contentar-me-ei com a referência a quatro correntes que se destacam no debate: a ideia humboldtiana de formação, a usurpação (neo-)liberal do sistema educativo, a pedagogia de resistência e a orientação por critérios burocrático-formais. Mais uma vez: quero interpretar essas correntes em primeira linha como caminhos de reduzir a complexidade crescente do sistema educativo. Não é por acaso que os profissionais da área tendam a identificar-se com uma ou outra dessas correntes, esperando, com isso, que seja possível tornar o espaço pedagógico mais transparente e criterioso para seu trabalho no dia a dia.

A primeira e mais tradicional diretriz pedagógica é, sem dúvida, a opção formulada por W. v. Humboldt. Segundo esse pedagogo e político da primeira parte do século XIX, a educação deveria ser considerada um processo de formação amplo do educando. À base dessa convicção, seria prioritário o desenvolvimento do potencial de cada aluno; ele é que deveria estar no centro da preocupação do educador. Ao Estado competiria implementar apenas uma política educativa que oferecesse ao educando múltiplas oportunidades para experimentar e explorar seu próprio potencial. Com esse foco, a concepção de Humboldt segue a linha do pensamento iluminista, segundo o qual o ser humano é considerado, em princípio, um ser racional e autônomo, cabendo à educação levar os educandos a esse "estágio de maioridade" (KANT, 1988, p. 8). Por mais natural que pareça essa tarefa, sua realização não é nada fácil, pois ela entra em choque com outras diretrizes pedagógicas, entre as quais, a visão economicista, que tenta submeter os indivíduos a fins que lhes são alheios: aumento da produtividade material, racionalização dos processos de trabalho e outros. O conflito é visível em momentos de crise, quando os pedagogos mais refletidos recorrem às ideias pedagógicas de Kant e Humboldt para defender-se das pressões econômicas e financeiras. Lembro, por exemplo, os debates sobre a primazia da profissionalização como aprendizagem técnica em detrimento da ideia 
de formação plena; sobre a legitimação da pesquisa científica por fins políticos; sobre os critérios quantificadores na avaliação dos resultados da educação escolar; ou sobre o financiamento de instituições de pesquisa pela indústria.

Temos aí que a orientação (neo-)liberal da educação representa a segunda diretriz orientadora no campo pedagógico tão complexo. Ela prioriza a lógica econômica e as necessidades intrínsecas ao mercado de trabalho. Incluir o indivíduo no processo econômico é seu fim primordial, um fim que se reflete, por exemplo, na diferenciação cada vez mais difusa de imagens profissionais. Querendo satisfazer as demandas provindas do mercado de trabalho, a "produção" de profissionais ignora os demais objetivos da formação. Por mais atraente que pareça ser a chance de lidar com uma só diretriz num campo complexo, a validade exclusiva da lógica econômica deixa claro o preço a pagar: ela leva a que a educação transforme-se em adestramento dos educandos com o objetivo de satisfazer, ao máximo possível, as expectativas dessa lógica material.

Conhecida como "pedagogia de resistência" (ADORNO, 2000), a terceira concepção pedagógica a ser lembrada nesse contexto defende a competência social, o desenvolvimento do espírito crítico e a sensibilização para com a ideia da solidariedade social como objetivos principais da educação. Ela dá importância maior à oportunidade de os educandos viverem a educação como espaço de experiências sociais. A formação dos jovens é projetada como caminho que passa da análise do status quo do mundo administrado para sua crítica emancipatória, focalizada no vencimento da racionalidade instrumental que faz das pessoas seus meros epifenômenos. Na pedagogia de resistência, tanto conteúdos quanto procedimentos da formação são expostos à revisão permanente, evitando-se, assim, o risco de uma sua petrificação. A linha orientadora dessa concepção consiste na reformulação contínua do espaço pedagógico, isto é - para usar uma fórmula aparentemente paradoxal -, na continuidade de mudanças permanentes. Eis seu fio condutor diante da dinâmica da modernização social.

O quarto e último critério, com a função de dirigir o sistema educativo, recorre à racionalidade burocrática, uma racionalidade que até hoje parece ser subestimada. Seu objetivo principal visa, antes de tudo, a preservar as instituições pedagógicas e garantir, custe o que custar, o cumprimento das regras legais que determinam o espaço do agir profissional. Por um lado, provocando uma restrição da atuação profissional contestada por muitos educadores, esse referencial traz consigo, por outro, uma vantagem que não pode ser subestimada: a orientação principal pelas regras legais restringe também a responsabilidade pessoal. Quem cumpre as regras burocrático-legais não é responsabilizado por possíveis efeitos negativos de seu agir profissional. É que a camisa de força das regras burocráticas 
tem uma cabeça de Janus: de uma parte, dificulta qualquer inovação pedagógica que, por ser inovadora, muitas vezes não se enquadra no marco burocrático; de outra, porém, dá segurança para o profissional que não quer experimentar caminhos novos e expor-se, assim, ao risco de fracassar.

Conflitos entre os profissionais da área da educação e os burocratas que a administram são frequentes. Ao fundo, esses conflitos giram em torno da primazia dada ou ao caráter inovador do trabalho pedagógico ou, ainda, à segurança profissional no campo educativo (SCOTT, 1966) Graças à sua função desresponsabilizadora, a orientação pelas regras burocráticas oferece o fio condutor mais claro e consistente à atuação dos educadores. Por isso mesmo, ela atrai tantos profissionais - sobretudo os mais expertos - como meio de driblar os riscos de fracassar diante da complexidade inacessível do espaço pedagógico.

Qualquer que seja a preferência dada a uma das diretrizes acima referidas, a escolhida sempre leva ao desprezo dos demais referenciais essenciais do espaço pedagógico. Daí se entendem os conflitos que movimentam os debates na Pedagogia. A pretensão de exclusividade, impulso da defesa de cada uma das diretrizes, resulta na concorrência árdua entre elas, uma concorrência que perde de vista que cada uma das correntes traz razões fortes em seu favor.

Resumindo, qualquer estratégia de reduzir a complexidade do espaço pedagógico facilita, de fato, o trabalho tanto de seus administradores quanto dos educadores. Porém, ao levar a efeito essas estratégias, a educação transforma-se em uma prática unidimensional que ignora a dinâmica da modernização social e a heterogeneidade dos desafios por ela lançados. O recurso à teoria de sistemas facilita o entendimento dessas insuficiências, obrigando as políticas de educação a reagir a essa constelação difusa. Querendo vencê-la, os políticos buscam as estratégias mais adequadas; sua avaliação será tema da terceira e última seção.

\section{Reações políticas: entre centralização e mercado livre}

Como se viu, reduzir a complexidade significa buscar pistas de orientação num sistema não acessível no seu todo. Existem, em princípio, duas opções extremas. A estratégia aparentemente mais simples é a unificação dos critérios e procedimentos que determinam o trabalho profissional; como opção forçada, ela se sobrepõe à complexidade real. O outro extremo consiste em admitir um leque amplo de diretrizes; entrando em concorrência entre si, elas podem apontar a alternativas e inovações em vista das condições concretas de seu campo de intervenção. Aceita-se, com essa opção, a criação de um mercado concorrido, com problemas de 
orientação para seus operadores. É claro que é possível buscar, também, caminhos intermediários entre os extremos.

Para a educação, a situação não é diferente, de modo que ela recorre às mesmas estratégias. A unificação e a centralização das diretrizes educativas para poder lidar com um campo pedagógico complexo e de fato inacessível para seus operadores correspondem ao caminho recentemente escolhido pelos países europeus. O Processo de Bologna - eis a fórmula na qual a estratégia unificadora se expressa -, implementado e aperfeiçoado desde 1999, tentou facilitar a orientação tanto dos alunos quanto dos educadores e administradores que agem no espaço pedagógico. Querendo substituir os modelos nacionais em parte incompatíveis entre si, a política educativa europeia optou pela assimilação dos sistemas e critérios, pela sua permeabilidade mútua e pelo reconhecimento geral dos resultados em nível europeu. Ora, não se pode negar os efeitos positivos dessa política, efeitos que consistem, em primeira linha, na transparência das regras formais e institucionais, na simplificação das decisões e na flexibilidade do acesso das pessoas ao mercado de trabalho europeu. Contudo, ao avesso dessa estratégia de reduzir a complexidade, constam perdas graves, pois a unificação formal do espaço pedagógico traz consigo a tendência de os operadores do sistema concentrarem-se no cumprimento dos critérios formais e procedimentais, deslocando a preocupação com a qualidade do ensino, da pesquisa e da formação para o segundo plano. Não contam mais o aprofundamento do saber e a postura reflexiva, a participação dos professores e dos alunos na sua produção, nem a ponderação de alternativas; ao contrário, a estratégia niveladora gratifica a oferta e o consumo de conhecimentos pré-moldados em manuais e de ideias correntes.

A postura receptiva no lugar da produção própria, a abreviação da formação profissional no lugar da reflexão sistemática, a aceitação cega de conteúdos no lugar do olhar crítico - eis apenas alguns dos efeitos negativos causados por essa estratégia. O objetivo de simplificar o manejo de um cenário de alta complexidade mediante sua centralização tem aí prioridade em relação à luta pela concepção pedagógica melhor. Em consequência disso, a política educativa oscila entre as demandas da racionalidade burocrática e o desafio de qualificar o trabalho pedagógico. Não pode surpreender, portanto, que os efeitos referidos da estratégia unificadora levassem, ultimamente, a críticas duras, obrigando a política europeia a revê-la.

À contramão dessa política, a tendência predominante no Brasil aponta ao fortalecimento da descentralização da responsabilidade no sistema educativo, uma tendência que é favorecida, historicamente, pela participação majoritária de instituições particulares diante das tradicionais dificuldades de o Estado sustentar uma rede pública abrangente e de qualidade. Quando o Estado entrou como ope- 
rador de peso no campo educacional - a partir dos anos 30 do século passado -, as instituições por ele mantidas aumentaram a complexidade do cenário já antes pouco transparente. Pois agora não foram apenas as instituições privadas que, desde sempre, concorreram entre si; foi, de repente, também a concorrência entre estas e as instituições estatais que levou o campo pedagógico a sofrer uma forte diferenciação tanto ideológica quanto cultural e conceptual. É por isso que o sistema educativo no Brasil dificulta e até impede qualquer estratégia centralizadora e uniformizante. $\mathrm{Na}$ verdade, ele se viu obrigado a entregar-se à lógica do mercado como condição de seu funcionamento em nível nacional.

Uma vez suposta essa diagnose, a política de educação não tem outra chance a não ser a de ceder autonomia maior às instituições pedagógicas existentes. Hoje, não são apenas as universidades alvo dessa política que leva à sua autonomia ideológica e econômica; constatam-se, atualmente, também iniciativas de implementar a mesma política em relação às redes escolares, provocando a forte resistência das respectivas categorias profissionais. Trata-se de uma estratégia que, além de confiar na "mão invisível" do mercado, passa a responsabilidade pelo sucesso do sistema educativo às mãos das instituições, cujo controle pela política reduz-se cada vez mais a questões de procedimentos formais. Manejada pela lógica do mercado, a complexidade do espaço pedagógico abre aí a chance de o poder público desresponsabilizar-se quanto a efeitos problemáticos dessa estratégia. $\mathrm{E}$, de fato, os efeitos negativos não são poucos. Quero mencionar apenas dois, a saber, a sedução ideológica das instituições de ensino e o risco do reforço da segregação social.

No que se refere ao risco da sedução ideológica, é oportuno remeter à história da pedagogia brasileira e ao princípio da subsidiariedade. A história do Brasil deu grande peso tanto quantitativo quanto qualitativo às instituições de ensino privadas, mantidas, em geral, pelas mais diversas organizações e ligas filantrópicas, que, mesmo favorecidas por recursos vindos do orçamento público, inscrevem na sua práxis pedagógica os princípios ideológicos por elas defendidos. Não são apenas as Igrejas que fazem parte desse mercado, senão - e cada vez mais - organizações e empresas em defesa dos mais difusos objetivos. Por mais problemática que essa diversidade ideológica seja, o engajamento desses operadores é bem visto por um Estado que tem dificuldades de providenciar e sustentar um sistema educativo abrangente e efetivo. E como se isso não bastasse, o princípio legal da subsidiariedade que, na política social, dá prioridade às atividades de organizações privadas diante da atuação do Estado, leva a que o Estado se veja obrigado a financiar, em grande parte, esse mercado de ideologias de difícil controle. Ainda que lhe caiba supervisionar esse mercado, o Estado não tem maior interesse de intensificar o 
controle para não correr o risco de perder a contribuição importante de serviços pedagógicos privados ao sistema educativo como um todo.

A segunda consequência negativa que o mercado de ofertas pedagógicas vem criando é sua contribuição involuntária à segregação social. Ainda hoje, a formação pessoal é vista como caminho importante da ascensão social, por isso existe uma disposição forte de as pessoas investirem nesse campo. Desde a pré-escola até a formação acadêmica, a economicização do sistema da educação favorece quem tem as condições de participar nesse mercado. Os efeitos curiosos dessa lógica são evidentes: quem tem o poder econômico para comprar desde cedo um bom serviço na escola privada vê aumentar sua chance de entrar na instituição acadêmica pública - que é gratuita. Quem não tem recursos suficientes para pagar uma formação escolar boa, dependendo da rede escolar pública - mas gratuita -, tem pouca chance de acesso à universidade pública; ele terá de entrar numa faculdade particular, pagando uma mensalidade que, não raro, excede seu orçamento individual. Trata-se de um modelo mercantil cuja dinâmica reforça a segregação social, na medida em que define as chances de frequentar o mercado.

É verdade que, ao longo das últimas duas décadas, a política de educação no Brasil não poupou esforços de fugir da alternativa entre a centralização e a aceitação da lógica do mercado, pois cada estratégia extrema traz consigo, ao seu avesso, problemas sérios tanto em termos sociais quanto no que se refere à qualidade pedagógica. A introdução de cotas para determinados grupos vulneráveis; a cessão de bolsas para famílias pobres; a promoção de alunos da rede estatal de ensino - várias são as tentativas de evitar as armadilhas do sistema atual. Todavia, por mais bem intencionadas que sejam, essas tentativas têm um efeito não bem-vindo: elas contribuem, por sua vez, para aumentar a complexidade do sistema em vez de reduzi-la, um fato que contradiz a estratégia de "reduzir a complexidade". Seja qual for a opção da política educativa a fim de tratar a complexidade do campo pedagógico, ela tem de contar com uma armadilha inevitável. Esse é seu dilema.

Como se vê, nenhuma das estratégias de manejar a complexidade do espaço pedagógico consegue apresentar a via régia, fato este, portanto, que tem de ser levado em conta por qualquer política realista. 


\section{The education faced with the complexity of contemporary society}

\section{Abstract}

To access the complexity of modern society, we must resort to the General Theory of the Systems, especially to the conception of "complexity reduction", defended by Niklas Lhumann. In this theory basis, the discussion between the main pedagogical visions is interpreted as a discussion about the most adequate way of reduce the complexity that is a characteristic of today's education field. Facing this cenario, the educational policies must seek solutions. However, not even the European centralization of the educational system, nor the Brazilian strategy that strengthens the concurrency between scholar institutions provide the escape to the intrinsic trap of any way of reduce the complexity.

Keywords: Complexity. Education. Educational policies.

\section{Referências}

ADORNO, Th. W. Erziehung nach Auschwitz. In: Gesammelte Schriften, Band 9/II. Frankfurt am Main: Suhrkamp, 1971. Versão portuguesa: Educação para a emancipação. Trad. de Wolfgang Leo Maar. Rio de Janeiro: Paz e Terra, 2000.

BECK, Ulrich. Risikogesellschaft. Frankfurt am Main: Suhrkamp, 1988. Versão portuguesa: Sociedade de risco: rumo a uma outra modernidade. Trad. de Sebastião Nascimento. São Paulo: Editora 34, 2010.

BERTALANFFY, Ludwig Von. Teoria geral de sistemas. Petrópolis, RJ: Vozes, 1977.

KANT, I. A paz perpétua e outros opúsculos. Trad. de Artur Morão. Lisboa: Edições 70, 1988.

LUHMANN, Niklas. Vertrauen. Ein Mechanismus der Reduktion sozialer Komplexität (Confiança: um mecanismo de redução da complexidade social). Stuttgart: Reclam, 1968.

SCOTT, Richard. Professionals in bureaucracies. In: VOLLMER, H.; HILLS, D. (Orgs.). Professionalization. New Jersey: Prentice Hall, 1966. p. 265 - 275. 